Article

\title{
Low-Field NMR and MRI to Analyze the Effect of Edible Coating Incorporated with MAP on Qualities of Half-Smooth Tongue Sole (Cynoglossus Semilaevis Günther) Fillets during Refrigerated Storage
}

\author{
Na Li 1,2,3, Yong Shen 1,2,3, Wenru Liu 1,2,3, Jun Mei 1,2,3,* and Jing Xie 1,2,3,* \\ 1 Shanghai Engineering Research Center of Aquatic Product Processing \& Preservation, Shanghai Professional \\ Technology Service Platform on Cold Chain Equipment Performance and Energy Saving Evaluation, \\ Shanghai 201306, China; linaxsyj@foxmail.com (N.L.); syshou@163.com (Y.S.); liuwenru0714@163.com (W.L.) \\ 2 National Experimental Teaching Demonstration Center for Food Science and Engineering, Shanghai Ocean \\ University, Shanghai 201306, China \\ 3 College of Food Science and Technology, Shanghai Ocean University, Shanghai 201306, China \\ * Correspondence: delightmay@hotmail.com (J.M.); jxie@shou.edu.cn (J.X.)
}

Received: 30 July 2018; Accepted: 15 August 2018; Published: 17 August 2018

check for updates

Featured Application: The monitoring of quality characteristics of Half-smooth tongue sole (HTS, Cynoglossus semilaevis Günther) is essential during refrigerated period based on the edible coating incorporated with MAP treatment, which has not displayed in the previous literatures. Meanwhile, the low-field nuclear magnetic resonance (LF-NMR) and magnetic resonance imaging (MRI) technology has a potential development to assess the quality of aquatic products, which is applied to assess the water distribution and migration of HTS fillets during 24-day storage. This study demonstrate that results of LF-NMR and MRI have the close connection with the physicochemical parameter of HTS fillets and can be applied to monitor water migration in a noninvasive and fast way.

\begin{abstract}
Nondestructive and fast measurement and characterization of fish is highly desired during various processing treatments. This research investigated the effectiveness of low field LF-NMR and MRI as fast monitoring techniques to estimate the qualities of half-smooth tongue sole fillets treated with edible coating combined with modified atmosphere packaging during refrigeration. $T_{2}$ relaxation spectra showed three peaks representing bound water $\left(T_{21}\right)$, immobile water $\left(T_{22}\right)$, and free water $\left(\mathrm{T}_{23}\right)$, respectively. $\mathrm{pT}_{22}$ accounted for the largest proportion of three types of water, followed by $\mathrm{pT}_{23}$. The weighted MRI provided the internal structure information associated with different samples, indicting the combination of edible coating and MAP $\left(70 \% \mathrm{CO}_{2}+30 \% \mathrm{~N}_{2}\right)$ is the best performance in the maintenance of qualities and freshness of HTS fillets. All results demonstrated that the combination of LF-NMR and MRI as fast and nondestructive methods have great potential to monitor qualities deterioration and predict shelf life in of HTS fillets during refrigerated storage.
\end{abstract}

Keywords: half-smooth tongue sole; LF-NMR; edible coating; modified atmosphere packaging

\section{Introduction}

Fish fillets is a highly perishable product due to its high water activity and protein content, neutral $\mathrm{pH}$, and presence of autolytic enzymes, resulting in deterioration of organoleptic properties and nutritional values, and eventually losing edibility [1]. Edible coating as an effective fresh-keeping method has been considered in aquatic products [2-4]. Rosmarinic acid (RA) is a natural polyphenol 
present in Lamiaceae herbs like Perilla frutescens with antioxidant, anti-inflammatory, and antimicrobial effect and has beneficial applications in improving shelf-life and imparting a desirable flavor to foodstuffs. $\varepsilon$-Polylysine ( $\varepsilon$-PL) as a natural antimicrobial polypeptide is recognized as safe preservative in foods [5]. Our previous studies have shown edible coating containing $30 \mathrm{mg} / \mathrm{kg}$ RA incorporated with $0.1 \% \varepsilon$-PL could effectively maintain the quality of HTS fillets during refrigeration. In addition, modified atmosphere packaging (MAP) is the process of filling with specific proportions of $\mathrm{CO}_{2}, \mathrm{~N}_{2}$, and $\mathrm{O}_{2}$ around a food product and then sealing that product in an impermeable package. Many published works indicated that MAP could be very proficient in extending the shelf-life of perishable foods especially fish products [6-8].

Different nondestructive analysis methods have been widely adopted to characterize the quality changes of raw fillets, such as near-infrared spectroscopy, X-ray computer tomography, hyperspectral imaging, frontface fluorescence spectroscopy, and so on [9]. However, low-field NMR (LF-NMR) and magnetic resonance imaging (MRI) techniques have more advantages in decreasing cost, saving time, and reducing damage to samples compared with the above instruments $[4,10,11]$. In addition, LF-NMR and MRI are able to assess the quality changes by providing the distribution as well as structural information of protons from water and lipid [12-14].

Half-smooth tongue sole (HTS, Cynoglossus semilaevis Günther) is rich in high-quality protein and polyunsaturated free fatty acids, and is emerging as one of the most valuable marine aquatic species in Northern China [12]. With the development of electronic commerce, the convenient and fast consumption mode is pursued by residents, and fresh fish fillets will become a main marketing form of fish products [1]. However, HTS decompose easily by environmental factors due to nutrient-rich character, and eventually lose edibility. Therefore, the principal objectives of the present study were to evaluate the quality effects of composite edible coating incorporated with MAP on HTS fillets during cold storage, and then investigated the effectiveness of low field LF-NMR and MRI as fast monitoring techniques to estimate the qualities of half-smooth tongue sole fillets during refrigerated storage $\left(4 \pm 0.5^{\circ} \mathrm{C}\right)$.

\section{Material and Methods}

\subsection{Preparation of Edible Coating Solution}

Bioactive edible coating solutions were prepared containing RA (Aladdin Biochemistry Technology Co., Ltd., Shanghai, China) and $\varepsilon$-PL (Sinopharm Chemical Reagent Co., Ltd., Shanghai, China). Certain amounts of RA and PL were separately dissolved in distilled water to prepare RA solution $(60 \mathrm{mg} / \mathrm{kg})$ and $\varepsilon$-PL solution $(2 \%, w / v)$. Equal volumes of RA solution and $\varepsilon$-PL solution were mixed and homogenized with magnetic stirring (Shanghai Siro Instruments Co., Ltd., Shanghai, China) to dissolve completely. The final concentration of RA was $30 \mathrm{mg} / \mathrm{kg}$, and the final concentration of $\varepsilon-\mathrm{PL}$ was $0.1 \%(w / v)$.

\subsection{Immersion Treatment of Fillets}

Fresh HTS (weight: $0.75 \pm 0.05 \mathrm{~kg}$; length: $40 \pm 2 \mathrm{~cm}$ ) were purchased from the wholesale aquatic market of Luchao Port (Shanghai, China) and immediately transported to the laboratory with ice within $30 \mathrm{~min}$. The fresh HTS had excellent physical properties and the head, bone, and skin were removed. Fillets with $6 \times 4 \times 1 \mathrm{~cm}$, weighing approximately $40 \mathrm{~g}$ were cut and prepared. Fillets were randomly separated into five treatments: the first one without any treatment was used as control (CK1) and other four groups were immersed in freshly prepared bioactive edible coating solution (ratio of coating solution to fish samples, 2:1, v/w) for $30 \mathrm{~s}$, then removed and allowed to drain at $4{ }^{\circ} \mathrm{C}$ around $30 \mathrm{~min}$ in order to form the coatings on the surface of fillets. All the samples were packed in polyethylene bags and coated groups submitted to the following modified atmosphere packaging (MAP) treatment. 


\subsection{MAP Treatment of Fillets}

Coated samples were treated with four packaging conditions: air packaging (CK2) and modified atmosphere treatment $\left(60 \% \mathrm{CO}_{2} / 40 \% \mathrm{~N}_{2}: \mathrm{C} 1 ; 65 \% \mathrm{CO}_{2} / 35 \% \mathrm{~N}_{2}: \mathrm{C} 2 ; 70 \% \mathrm{CO}_{2} / 30 \% \mathrm{~N}_{2}\right.$ : $\left.\mathrm{C} 3\right)$ using a thermos-sealing equipment (DQB-360W, Qingba Food Packaging Machinery Co., Ltd., Shanghai, China) with a gas-product ratio 2:1. Extraction time was $15 \mathrm{~s}$, aeration time was $5 \mathrm{~s}$, electrothermal sealing temperature was $140{ }^{\circ} \mathrm{C}$, gas mixing accuracy $<2 \%$, power gas source was $0.714 \mathrm{MPA}$, mixed fresh gas pressure was $0.408 \mathrm{MPa}$, and fresh gas source pressure was $0.51 \mathrm{MPa}$. All samples were stored at $4{ }^{\circ} \mathrm{C}$ for subsequent assessments at 4 -day intervals.

\subsection{LF-NMR Analysis}

Analysis was performed according to the method proposed by Huang et al. [11] with following modifications. Portions of $3 \times 3 \times 1 \mathrm{~cm}$ (about $5 \mathrm{~g}$ ) were cut from the dorsal part of fillets and sealed with polyethylene films. The samples were placed in NMR tubes (70 $\mathrm{mm}$ diameter). Transverse relaxation $\mathrm{T}_{2}$ measurements were recorded on a LF NMR analyzer (MesoMR23-060H.I, Niumag Corporation, Suzhou, China) with a proton resonance frequency of $20 \mathrm{MHz}$, corresponding to the pulse sequence of Carr-Purcell-Meiboom-Gill (CPMG) and the primary parameters were as follows. SW (the receiver bandwidth frequency) $=100 \mathrm{kHz}$, RFD (the parameter to control the first data point that acquired) $=0.08$, the number of the scans NS $=4, \mathrm{P} 1=18 \mu \mathrm{s}, \mathrm{P} 2=36 \mu \mathrm{s}, \mathrm{RG} 1$ (analog gain) $=20 \mathrm{db}$, DRG1 (digital gain) $=6 \mathrm{db}$, PRG (preamplifier gain) $=0$, delay DL1 $=0.2 \mathrm{~ms}$, and TW (the duration between successive scans) $=2000 \mathrm{~ms}$. Three pieces of fillet samples were measured for every sample group.

\subsection{MRI Analysis}

MRI experiments of all samples were also implemented by the LF-NMR analyzer (MesoMR23-060H.I, Niumag Electronic Technology Co., Ltd., Shanghai, China) to obtain proton density weighted images. Acquisition parameters were showed as follows. Slice width $=3 \mathrm{~mm}$, $\mathrm{TR}($ time repetition $)=2000$, and TE $($ time echo $)=15 \mathrm{~ms}$. Three images were taken for each sample and three pieces of fillet samples were measured for each group.

\subsection{Water Content}

The water content were determined according to the Chinese standard (GB 5009.3-2016). Specifically, 2-10 g sample was precisely weighted and dried at $105{ }^{\circ} \mathrm{C}$ to constant weight. The percentage of water content was calculated according to the weight before drying and after drying. Three replicates were made from every group and mean value was considered as the final result.

\subsection{Fat Content}

The fat content were determined according to the Chinese standard (GB 5009.6-2016). Briefly, $2.0 \mathrm{~g}$ of drying sample was dripped in $40 \mathrm{~mL}$ anhydrous ether and refluxed at $65^{\circ} \mathrm{C}$ for $8 \mathrm{~h}$ and constantly solvent was removed at $65^{\circ} \mathrm{C}$ for $3 \mathrm{~h}$ in the vacuum environment. The percentage of fat content was determined according to the weight before and after extraction. Three replicates were carried out of every group and the mean value was considered as the final result.

\subsection{TVB-N Value}

The total volatile basic nitrogen (TVB-N) values were determined according to the Chinese standard (GB 5009.228-2016). The TVB-N values of fish samples were evaluated using an automatic Kjeldahl nitrogen-determination instrument (Kjeltec8400, Foss, Denmark) and were expressed in mg $\mathrm{N} / 100 \mathrm{~g}$. Three replicates were carried out of every group and the mean value was considered as the final result. 


\subsection{K Value}

The determinations of nucleotides and related compounds were carried out referred to the method as proposed by Su et al. [15], using a RP-HPLC procedure (Waters 2695, Milford, CT, USA). The K value was calculated as follows:

$$
\mathrm{K} \text { value }(\%)=\frac{\mathrm{HxR}+\mathrm{Hx}}{\mathrm{ATP}+\mathrm{ADP}+\mathrm{AMP}+\mathrm{IMP}+\mathrm{HxR}+\mathrm{Hx}} \times 100
$$

\subsection{0. $\mathrm{Ca}^{2+}$-ATPase Activity}

The extraction of actomyosin was performed as described by Sun et al. [14], with slight modifications. Briefly, fillet samples of $1 \mathrm{~g}$ were mixed and homogenized with $10 \mathrm{~mL}$ precooled $\mathrm{KCl}$ solution $(0.6 \mathrm{~mol} / \mathrm{L}, \mathrm{pH} 7.0)$ and then the homogenate was centrifuged at 10,000 r/min for $20 \mathrm{~min}$ in $4{ }^{\circ} \mathrm{C}$, then the supernatant was added to three fold volume cooled distilled water and centrifuged at $10,000 \mathrm{r} / \mathrm{min}$ for $20 \mathrm{~min}$. The supernatant was discarded and precipitate was added to the same volume precooled $\mathrm{KCl}$ solution $(1.2 \mathrm{~mol} / \mathrm{L}, \mathrm{pH} 7.0)$ to dissolve completely the actomyosin. The solution was centrifuged at $8000 \mathrm{r} / \mathrm{min}$ for $20 \mathrm{~min}$ to remove the insoluble protein. The supernatant was actomyosin and $\mathrm{Ca}^{2+}$-ATPase activity was measured using $\mathrm{Ca}^{2+}$-ATPase kit (Nanjing Jiancheng Bioengineering Institute, Nanjing, China). Three replicates were carried out of every group and the mean value was considered as the final result.

\subsection{Malondialdehyde (MDA) Value}

The MDA value was determined by MDA kit according to the instructions (Nanjing Jiancheng Bioengineering Institute, Nanjing, China). Three replicates were carried out of every group and the mean value was considered as the final result.

\subsection{Sensory Scores}

The organoleptic properties of HTS fillets samples were evaluated and a panel of ten trained members (five woman and five men, aged 20-30 years) from the laboratory staff participated. Panelists were asked to evaluate the color, odor, tissue morphology, elasticity and mucus using a five-point scale: 5 corresponded to 'most liked' and 1 to 'most disliked'. Shelf life criteria assumed that rejection would occur when the sensory attributes declined below 5.0.

\subsection{Statistical Analysis}

Distributed multiexponential fitting of CPMG and IR decay curves was performed in MultiExp Inv analysis software (Niumag Electric Corporation, Shanghai, China). Experimental data were analyzed using SPSS software (version 19.0, Statistical Package for the Social Sciences Inc., Chicago, IL, USA). The one-way ANOVA procedure followed by Duncan's multiple range tests was adopted to determine the significant difference $(p<0.05)$ between treatment means, and the results were expressed as means \pm SD.

\section{Results and Discussion}

\subsection{Quality Attributes}

The changes of sensory and physicochemical qualities of HTS fillets were evaluated during storage. Organoleptic properties play great role in consumer acceptance and marketability of food products. Fresh fish is among the most perishable foods due to lipid content, microbiological changes, and external factors [15]. Thereby maintaining its organoleptic characteristics becomes very important. As showed in Figure 1a, sensory scores decreased significantly with storage time in CK1, however, C2 and C3 had relatively slower reduction. This fact indicted that bioactive edible coating combined with MAP had promising effects on the maintenance of sensory attributes. 
(a)

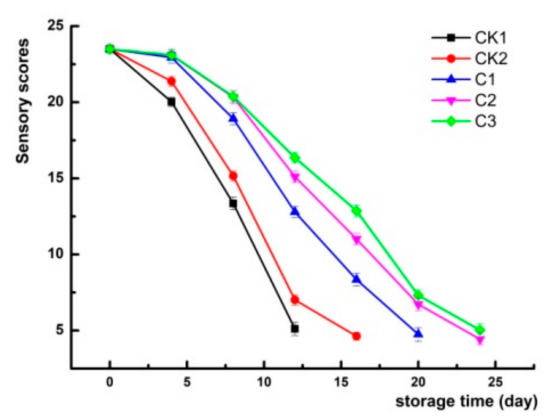

(c)

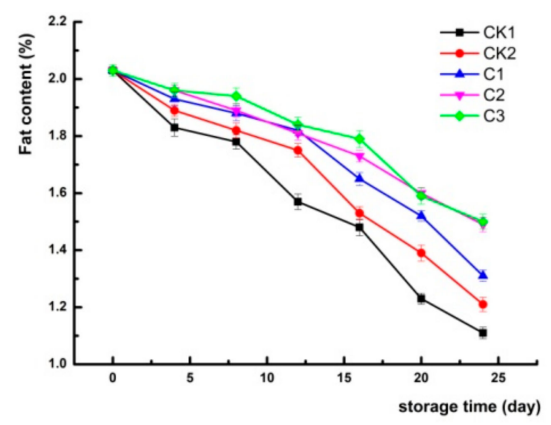

(e)

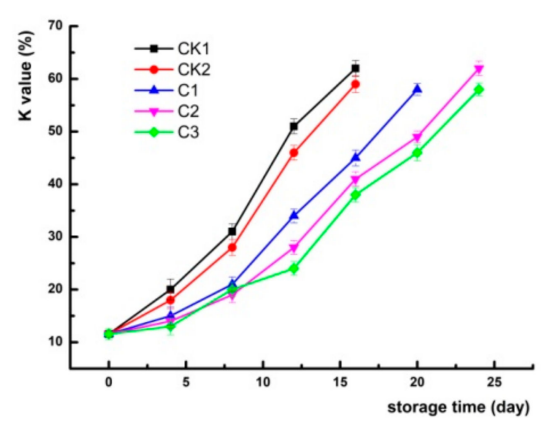

(g)

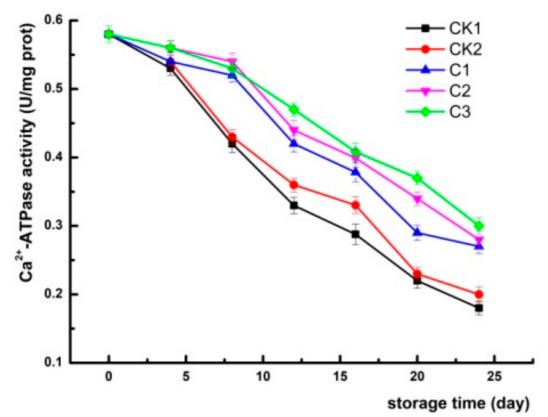

(b)

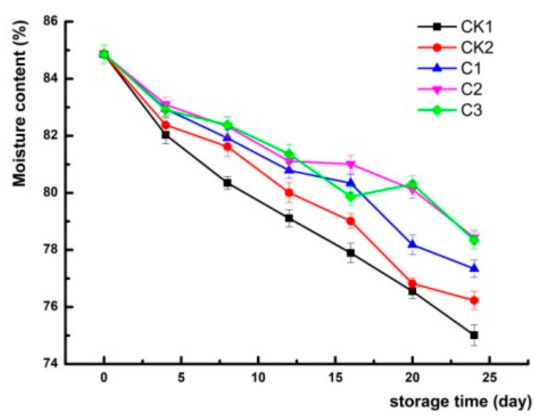

(d)

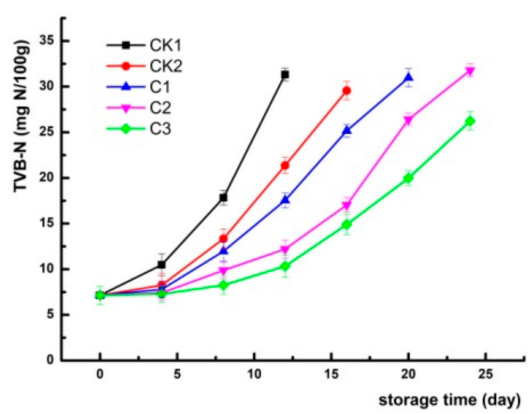

(f)

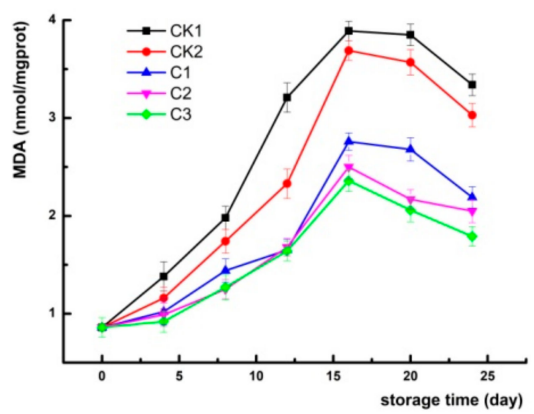

Figure 1. Changes in sensory scores (a), moisture content (b), fat content (c), and TVB-N value (d), K value (e), MDA (f) and activity of $\mathrm{Ca}_{2}+$-ATPase (g) of samples during refrigerated storage (CK1: distilled water + air packing; CK2: edible coating + air packing; C1: edible coating + MAP $\left(60 \% \mathrm{CO}_{2} / 40 \% \mathrm{~N}_{2}\right) ; \mathrm{C} 2$ : edible coating $+\mathrm{MAP}\left(65 \% \mathrm{CO}_{2} / 35 \% \mathrm{~N}_{2}\right)$; C3: edible coating $+\mathrm{MAP}(70 \%$ $\left.\mathrm{CO}_{2} / 30 \% \mathrm{~N}_{2}\right)$ ). 
Figure $1 \mathrm{~b}$ suggested that there was a gradual moisture content reduction in all samples during 24-day storage. Then the decrease rate of edible coating treated group combined with MAP was slower than that of CK1 and CK2. That may be the MAP provides an effective inbuilt water vapor barrier and prevents loss by evaporation [7]. The fat content with different treatments showed a similar trend with moisture content during storage (Figure 1c). Interestingly, there were no obvious differences between $\mathrm{C} 2$ and $\mathrm{C} 3$ during storage, indicating that $65 \% \mathrm{CO}_{2} / 35 \% \mathrm{~N}_{2}$ or $70 \% \mathrm{CO}_{2} / 30 \% \mathrm{~N}_{2}$ were suitable treatments of MAP combined with edible coating applied refrigerated HTS fillets.

TVB-N value is usually considered as an important index to assess the quality and shelf life of aquatic products [16]. As shown in Figure 1d, the initial at day 0 was $7.14 \mathrm{mg} / 100 \mathrm{~g}$ and there was an increase in all the samples during storage. The TVB-N value in CK1 reached an unaccepted level $(31.32 \mathrm{mg} / 100 \mathrm{~g})$ on the 12th day and the samples with MAP incorporated with bioactive edible coating had lower TVB-N values compared with CK1 and CK2, especially $70 \% \mathrm{CO}_{2} / 30 \% \mathrm{~N}_{2}$ of MAP. The dominant reason was that the high concentration of $\mathrm{CO}_{2}$ could retard bacterial action in the conversion of trimethylamine oxide (TMAO) into trimethylamine (TMA), which was one of the main substrates for the production of volatile bases [17].

The $\mathrm{K}$ value is defined as the ratio of inosine $(\mathrm{HxR})$ plus hypoxanthine $(\mathrm{Hx})$ to the total adenosine triphosphate (ATP) and related compounds (ADP, AMP, IMP, HxR, and Hx) in fish muscle extract, reflecting the degree of nucleotide degradation [18]. As shown in Figure 1e, the initial $\mathrm{K}$ value of HTS fillets was $11.56 \%$. K values increased progressively $(p<0.05)$ over time for different treated samples because of the degradation of ATP to derivative compounds [1]. Generally, a K value of $60 \%$ fish muscle was taken as the highest acceptable level; as proposed by the European Commission [19]. Briefly, the $\mathrm{K}$ value of $\mathrm{CK} 1$ reached $62 \%$ at day 12 , while the $\mathrm{CK} 2, \mathrm{C} 1$, and $\mathrm{C} 2$ group exceeded this limitation at day 16, 20, and 24, respectively. The fact suggested that a high concentration of $\mathrm{CO}_{2}$ in the MAP environment could effectively retard the increased rate of $\mathrm{K}$ value and extend the shelf life of HTS fillets. Reports showed that the transformation process from IMP to Hx can be affected by spoilage bacteria [20]. Therefore, a high concentration of $\mathrm{CO}_{2}$ can suppress ATP breakdown via retarding the growth of microbial metabolism.

The amount of malonaldehyde (MDA) is commonly used to measure the level of rancidity and is mainly related to the accumulation of secondary products via liquid oxidation [20]. In the present study, the MDA value of CK1 increased gradually from $0.86 \mathrm{nmol} / \mathrm{mgprot}$ at day 0 to $3.89 \mathrm{nmol} / \mathrm{mgprot}$ at day 16 (Figure 1f). However, the samples treated with edible coating combined with MAP had lower values at the corresponding time, especially the gas composition of $65 \% \mathrm{CO}_{2} / 35 \% \mathrm{~N}_{2}$ or $70 \% \mathrm{CO}_{2} / 30 \%$ $\mathrm{N}_{2}$. Then the MDA value of all samples had a decrease at the end of storage as a consequence of the interaction between malonaldehyde and protein degradation products [21]. In general, the combined effect of edible coating and MAP $\left(65 \% \mathrm{CO}_{2} / 35 \% \mathrm{~N}_{2}\right.$ or $\left.70 \% \mathrm{CO}_{2} / 30 \% \mathrm{~N}_{2}\right)$ has positive effects on maintaining quality characteristics of HTS fillets.

The activity of $\mathrm{Ca}^{2+}$-ATPase is broadly used to assess the actomyosin integrity, reflecting the degradation of myofibrillar protein [14]. In the current study, a decreasing trend was detected no matter what kind of treatment was carried out during refrigerated storage (Figure 1g), which was concordance with the results with Pavap [22]. In comparison with the initial value, the activity of $\mathrm{Ca}^{2+}$-ATPase of CK1 group was diminished by $68.97 \%$ at the end of storage, while other samples showed more excellent influence on reduction of the activity of $\mathrm{Ca}^{2+}$-ATPase, especially the $\mathrm{C} 3$ group. This results may be related with conformation and aggregation of myosin globular head [23].

\subsection{Measurements of LF-NMR}

LF-NMR undoubtedly provided excellent prospects in predicting of quality characteristics and shelf life of aquatic products. Previous researches demonstrated that there was a close relationship between transverse relaxation $\mathrm{T}_{2}$ and traditional physicochemical parameters of the quality of muscle products [9]. Figure 2 showed the change trends of CPMG relaxation signal intensity at the beginning, middle, as well as the last stage of storage with different treatments. As mentioned in Figure 2, there 
was an obvious decreasing intensity in the curves with the storage time regardless of treated methods and no significant changes was not observed beyond $1000 \mathrm{~ms}$ of relaxation time. Meanwhile, the decreased rate of echoes of CK1 was higher than that of other treatments, especially samples treated with edible coating incorporated with $70 \% \mathrm{CO}_{2} / 30 \% \mathrm{~N}_{2}$ MAP. But Zang et al. reported that the curves of signal intensity could rarely provide a descending trend of signal amplitude and reflect information about the status and distribution of different types of water [9]. In fact, the information obtained from CPMG echoes as raw date was limited, and further analysis needs to be carried out to fully explain the diversification of the three types of water.

(a)

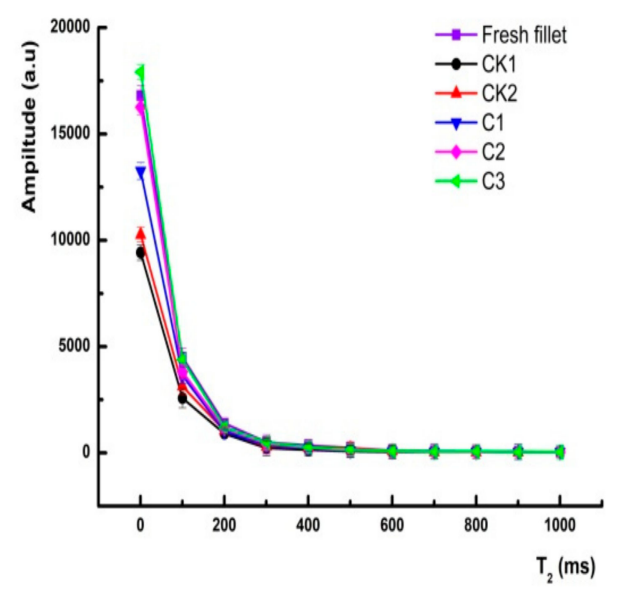

(b)

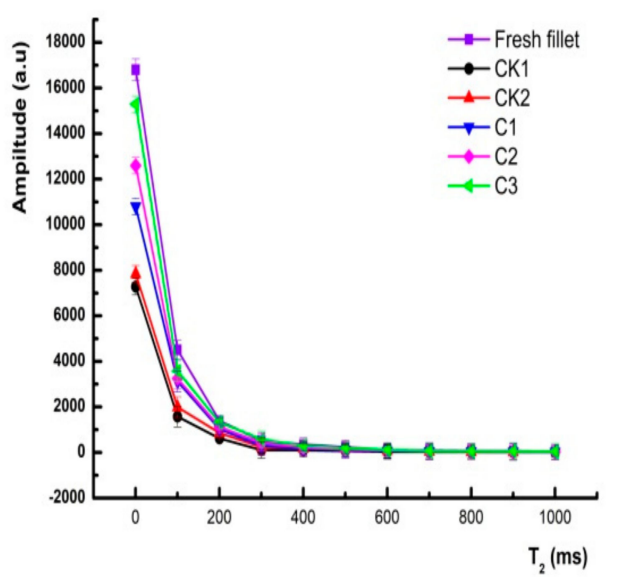

Figure 2. Changes in CPMG echoes of samples under different treatments on the 12th (a) and 24th day of the refrigerated period (CK1: distilled water + air packing; CK2: edible coating + air packing; $\mathrm{C} 1$ : edible coating $+\mathrm{MAP}\left(60 \% \mathrm{CO}_{2} / 40 \% \mathrm{~N}_{2}\right)$; $\mathrm{C} 2$ : edible coating $+\mathrm{MAP}\left(65 \% \mathrm{CO}_{2} / 35 \% \mathrm{~N}_{2}\right)$; C3: edible coating + MAP $\left.\left(70 \% \mathrm{CO}_{2} / 30 \% \mathrm{~N}_{2}\right)\right)$.

The multiexponential fitting of transverse relaxation $\mathrm{T}_{2}$ distribution was carried out by Origin software and the protons associated with three types of water were identified. These results were consistent with some researches $[14,16]$. As shown in Table 1 , the shortest relaxation time $T_{21}$ in the range of 1.32-6.14 ms was detected, representing the bound water entrapped within tertiary and quaternary protein structures. Besides, the intermediate population of $\mathrm{T}_{22}$ with a relaxation time of 28.48-117.38 ms considered as immobile water within the myofibril. Finally the third population, $\mathrm{T}_{23}$ in the range of 403.7-3274.55 ms corresponds to free water extramyofibrillar space [24]. Briefly, no significant differences were detected in $\mathrm{T}_{21}$ time among different treated samples in the current experiment, indicating transverse time $\mathrm{T}_{21}$ was not affected by treated methods as well as storage time. Wang previously pointed out that $\mathrm{T}_{22}$ diminished while $\mathrm{T}_{23}$ increase with time in muscle [16]. But the conclusions disagreed with the results in the present study. Briefly, $\mathrm{T}_{22}$ time of all samples fluctuated without regular trends; while $\mathrm{T}_{23}$ firstly declined steadily and increased constantly. This fact was also indicated that the changes of free water were more obvious than those of bound and immobile water with the extension of storage time. Interestingly, the range of relaxation time for the three types of water was slightly different among all samples during storage, which may related to the migration of moisture during storage. This prediction is further verified by the changes trends of peak area proportion of certain type of water. Furthermore, the $\mathrm{pT}_{21}, \mathrm{pT}_{22}$, and $\mathrm{pT}_{23}$ were corresponded to the areas of relaxation time $\mathrm{T}_{21}, \mathrm{~T}_{22}$, and $\mathrm{T}_{23}$. Obviously, $\mathrm{pT}_{21}$ almost rarely changed during the entire storage period, ranging from 1.74 to 1.96 . This behavior occurred due to the viewpoint that the water entrapped within highly organized myofibril structures and water in tertiary and quaternary protein structures were stable [25]. The $\mathrm{pT}_{22}$ diminished progressively while $\mathrm{pT}_{23}$ increased during storage, and $\mathrm{pT}_{22}$ accounted for the largest proportion of three types of water, followed by $\mathrm{pT}_{23}$. In the present study, The CK1 had significant lower immobilized water (from an initial value of $87.63 \%$ to $69.29 \%$ ) 
than that of other samples. No significant difference was observed of the amounts of the immobilized water in C3 $(p<0.05)$, probably owing to the conclusion that the combination effects of edible effects and MAP (gas composition of $70 \% \mathrm{CO}_{2} / 30 \% \mathrm{~N}_{2}$ ) enormously decreased the rate of diffusion of the immobilized water into free water and maintained excellent quality characteristics of the HTS fillets. Besides, this synergetic effect was well reflected in the fact that $\mathrm{pT}_{23}$ increased obviously during storage period. Furthermore, the samples treated with bioactive edible coating combined with MAP had lower content of free water than the control and edible coating group alone. Above all, we could conclude that the synergetic effects of the edible coating combined with MAP could effectively retard water located within the myofibrillar macromolecules to release or translate to free water based on the destruction of the muscle fiber and keep excellent quality attributes of the HTS fillets [14].

Table 1. Changes of transverse relaxation time and relative content of three water component in HTS fillets with different treatments during the refrigerated period.

\begin{tabular}{|c|c|c|c|c|c|c|}
\hline Storage Time (Day) & $\mathrm{T}_{21}(\mathrm{~ms})$ & $\mathrm{T}_{22}(\mathrm{~ms})$ & $\mathrm{T}_{23}(\mathrm{~ms})$ & $\mathrm{pT}_{21}$ & $\mathrm{pT}_{22}$ & $\mathrm{pT}_{23}$ \\
\hline $0 \mathrm{~d}$ & $0.079 \pm 0.002$ & $75.65 \pm 2.79$ & $1232.84 \pm 5.4$ & $1.96 \pm 0.13$ & $87.63 \pm 3.26$ & $10.41 \pm 0.56$ \\
\hline \multicolumn{7}{|l|}{$12 \mathrm{~d}$} \\
\hline CK1 & $0.15 \pm 0.02$ & $79.38 \pm 1.84$ & $932.60 \pm 3.82$ & $1.78 \pm 0.21$ & $77.83 \pm 2.18$ & $20.39 \pm 0.93$ \\
\hline CK2 & $0.064 \pm 0.003$ & $65.79 \pm 3.27$ & $717.13 \pm 4.92$ & $1.74 \pm 0.09$ & $79.19 \pm 2.84$ & $19.12 \pm 1.13$ \\
\hline $\mathrm{C} 1$ & $0.166 \pm 0.046$ & $75.83 \pm 2.64$ & $705.48 \pm 4.04$ & $1.84 \pm 0.34$ & $81.23 \pm 3.16$ & $16.93 \pm 0.92$ \\
\hline $\mathrm{C} 2$ & $0.194 \pm 0.032$ & $69.79 \pm 2.18$ & $533.67 \pm 1.84$ & $1.83 \pm 0.22$ & $84.98 \pm 2.21$ & $13.19 \pm 1.26$ \\
\hline $\mathrm{C} 3$ & $0.141 \pm 0.027$ & $73.93 \pm 2.35$ & $642.84 \pm 3.15$ & $1.74 \pm 0.13$ & $85.13 \pm 2.19$ & $13.11 \pm 1.17$ \\
\hline \multicolumn{7}{|l|}{$24 \mathrm{~d}$} \\
\hline CK1 & $0.15 \pm 0.026$ & $65.79 \pm 4.19$ & $1072.27 \pm 4.2$ & $1.84 \pm 0.08$ & $69.29 \pm 3.17$ & $28.87 \pm 1.04$ \\
\hline CK2 & $0.132 \pm 0.025$ & $73.19 \pm 2.83$ & $1232.85 \pm 6.8$ & $1.86 \pm 0.13$ & $70.54 \pm 2.56$ & $27.6 \pm 1.22$ \\
\hline $\mathrm{C} 1$ & $0.116 \pm 0.011$ & $86.97 \pm 3.62$ & $1417.48 \pm 3.2$ & $1.79 \pm 0.36$ & $73.19 \pm 3.9$ & $25.02 \pm 1.47$ \\
\hline $\mathrm{C} 2$ & $0.102 \pm 0.027$ & $68.59 \pm 2.91$ & $1069.57 \pm 5.6$ & $1.85 \pm 0.32$ & $79.92 \pm 2.89$ & $18.23 \pm 1.02$ \\
\hline $\mathrm{C} 3$ & $0.107 \pm 0.034$ & $74.27 \pm 3.15$ & $1243.38 \pm 3.9$ & $1.92 \pm 0.24$ & $80.18 \pm 3.04$ & $17.9 \pm 0.93$ \\
\hline
\end{tabular}

\subsection{Analysis of MRI}

MRI provides visual information on the spatial, internal morphological organization, and molecular distribution of in food matrix and has drawn great attention because of its rapid, direct, and accurate imaging characteristics in comparison with LF-NMR [26]. It is well-known that a red color represents high proton density while a blue color represents low proton density in the pseudo-color images. The $T_{2}$ proton density weighted images of samples with different treatments during refrigeration are shown in Figure 3. No significant difference was detected in images brightness of samples treated with edible coating combined with MAP at the beginning stage, while obvious changes occurred in the control group, especially CK1. From the 15th day, the color of CK1 was bluer and darker than that of other samples, as demonstrated by Wang et al. [16], which indicated the degradation of the myofibrils and destruction of the microstructure in CK1. Those results were consistent with the changes of transverse relaxation of LF-NMR. Above all, MRI is also a complementary technology for understanding water migration of HTS fillets during storage. On the other hand, results also confirmed that water distribution was correlated with the quality properties of HTS fillets. 


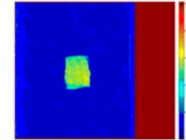

od

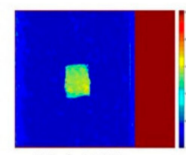

12d CK1

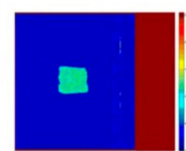

24d CK1

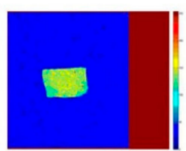

$12 \mathrm{~d}$ CK2

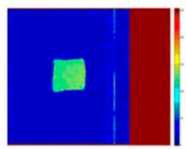

24d CK2

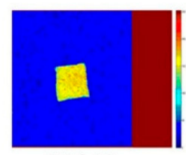

$12 \mathrm{~d} \mathrm{C1}$

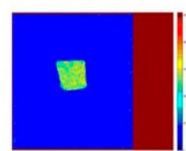

24d C1

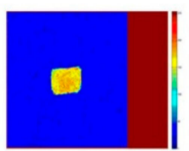

$12 \mathrm{~d}$ C2

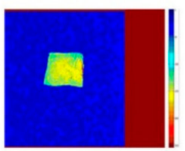

24d C2

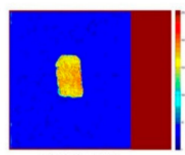

$12 \mathrm{~d} \mathrm{C} 3$

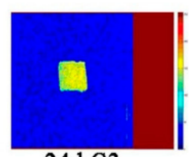

24d C3

Figure 3. Results of magnetic resonance imaging (MRI) of samples under different treatments during refrigerated storage (CK1: distilled water + air packing; CK2: edible coating + air packing; $\mathrm{C} 1$ : edible coating + MAP $\left(60 \% \mathrm{CO}_{2} / 40 \% \mathrm{~N}_{2}\right) ; \mathrm{C} 2$ : edible coating + $\mathrm{MAP}\left(65 \% \mathrm{CO}_{2} / 35 \% \mathrm{~N}_{2}\right)$; $\mathrm{C} 3$ : edible coating $\left.+\operatorname{MAP}\left(70 \% \mathrm{CO}_{2} / 30 \% \mathrm{~N}_{2}\right)\right)$.

\subsection{Linear Regression Analysis}

The potential of LF-NMR as predictor of quality characteristics has received substantial research interest and it has been perceived as an efficient technique to assess the freshness of aquatic products. Previous researches have also confirmed that LF-NMR measurements were associated with quality parameters, such as WHC, drip loss, color, and so on $[16,27,28]$. In the current study, the relationship between LF-NMR relaxation parameters and quality indexes was investigated during refrigerated storage (Table 2). Obviously, no relationship was detected among $\mathrm{pT}_{21}$ and the physicochemical parameters, suggesting that the value of $\mathrm{pT}_{21}$ was barely high enough to predict the quality characteristics of HTS fillets. However, a good correlation between $\mathrm{pT}_{22}, \mathrm{pT}_{23}$, and physicochemical parameters were detected. Briefly, the $\mathrm{pT}_{22}$ showed excellent correlation with $\mathrm{R}^{2}$ in the range of 0.79631-0.98873 with water contents, fat contents, and the activities of $\mathrm{Ca}^{2+}$-ATPase. While the TVB-N values and MDA values showed relatively poor relationship correlation with $\mathrm{pT}_{22}$. It also can be concluded that there was no relationship between $\mathrm{pT}_{22}$ and $\mathrm{K}$ values in all samples. By comparison, there was a significantly good correlation between $\mathrm{pT}_{23}$ and TVB-N, $\mathrm{K}$ value and MDA $(p<0.01)$. However, a poor relationship was detected between $\mathrm{pT}_{23}$ and water content or the activity of $\mathrm{Ca}^{2+}$-ATPase. No correlation was detected between $\mathrm{pT}_{23}$ and fat content. In general, $\mathrm{pT}_{22}$ plays a more important role in the evaluation of water contents, fat contents, and the activities of $\mathrm{Ca}^{2+}$-ATPase changes, while $\mathrm{pT}_{23}$ is more effective in assessing the qualities of TVB-N, K value, and MDA.

Table 2. Linear regression analysis of HTS fillets with different treatment during refrigerated storage.

\begin{tabular}{ccccccccc}
\hline Groups & $\mathbf{T}_{2}$ & & TVB-N & K Value & $\begin{array}{c}\text { Moisture } \\
\text { Content }\end{array}$ & $\begin{array}{c}\text { Fat } \\
\text { Content }\end{array}$ & $\begin{array}{c}\text { Activity of } \\
\text { Ca }^{2+} \text {-ATPase }\end{array}$ & MDA \\
\hline CK1 & $\mathrm{pT}_{21}$ & $\mathrm{R}$ & -0.116 & -0.252 & 0.376 & 0.257 & 0.334 & -0.356 \\
& & $\mathrm{R}^{2}$ & 0.01346 & 0.06351 & 0.14138 & 0.02146 & 0.111556 & 0.12674 \\
& & $\mathrm{p}$ & $\mathrm{ns}$ & $\mathrm{ns}$ & $\mathrm{ns}$ & $\mathrm{ns}$ & $\mathrm{ns}$ & $\mathrm{ns}$ \\
& $\mathrm{pT}_{22}$ & $\mathrm{R}$ & 0.95119 & 0.29514 & 0.92732 & 0.98812 & 0.98214 & 0.99312 \\
& & $\mathrm{R}^{2}$ & 0.90476 & 0.08711 & 0.85992 & 0.97638 & 0.9646 & 0.98629 \\
& & $\mathrm{p}$ & 0.05 & $\mathrm{~ns}$ & 0.01 & 0.01 & 0.01 & 0.05 \\
& $\mathrm{pT}_{23}$ & $\mathrm{R}$ & 0.86271 & 0.94352 & 0.84978 & 0.22136 & 0.94675 & 0.94978 \\
& & $\mathrm{R}^{2}$ & 0.74427 & 0.89023 & 0.72213 & 0.0449 & 0.89634 & 0.90208 \\
& & $\mathrm{p}$ & 0.01 & 0.01 & 0.05 & $\mathrm{~ns}$ & 0.05 & 0.01 \\
\hline
\end{tabular}


Table 2. Cont.

\begin{tabular}{|c|c|c|c|c|c|c|c|c|}
\hline Groups & $\mathrm{T}_{2}$ & & TVB-N & K Value & $\begin{array}{c}\text { Moisture } \\
\text { Content }\end{array}$ & $\begin{array}{c}\text { Fat } \\
\text { Content }\end{array}$ & $\begin{array}{c}\text { Activity of } \\
\mathrm{Ca}^{2+} \text {-ATPase }\end{array}$ & MDA \\
\hline \multirow[t]{9}{*}{ CK2 } & \multirow[t]{3}{*}{$\mathrm{pT}_{21}$} & $\mathrm{R}$ & 0.56437 & 0.34126 & 0.39643 & 0.23168 & 0.41154 & 0.28746 \\
\hline & & $\mathrm{R}^{2}$ & 0.31851 & 0.11646 & 0.15716 & 0.05367 & 0.16937 & 0.08263 \\
\hline & & $\mathrm{p}$ & ns & ns & ns & ns & ns & ns \\
\hline & \multirow[t]{3}{*}{$\mathrm{pT}_{22}$} & $\mathrm{R}$ & 0.38324 & 0.29435 & 0.93293 & 0.97317 & 0.97224 & 0.89146 \\
\hline & & $\mathrm{R}^{2}$ & 0.3705 & 0.08644 & 0.87036 & 0.94706 & 0.94525 & 0.7947 \\
\hline & & $\mathrm{p}$ & $\mathrm{ns}$ & ns & 0.01 & 0.01 & 0.01 & 0.05 \\
\hline & \multirow[t]{3}{*}{$\mathrm{pT}_{23}$} & $\mathrm{R}$ & 0.90213 & 0.97568 & 0.82514 & 0.28246 & 0.87412 & 0.93562 \\
\hline & & $\mathrm{R}^{2}$ & 0.81384 & 0.95195 & 0.68086 & 0.07978 & 0.76173 & 0.87539 \\
\hline & & $\mathrm{p}$ & 0.01 & 0.01 & 0.05 & ns & 0.05 & 0.01 \\
\hline \multirow[t]{9}{*}{$\mathrm{C} 1$} & \multirow{3}{*}{$\mathrm{pT}_{21}$} & $\mathrm{R}$ & 0.54873 & 0.28534 & 0.42674 & 0.32143 & 0.37892 & 0.29836 \\
\hline & & $\mathrm{R}^{2}$ & 0.30111 & 0.08142 & 0.18211 & 0.10332 & 0.14358 & 0.08902 \\
\hline & & $\mathrm{p}$ & ns & ns & ns & ns & ns & ns \\
\hline & \multirow[t]{3}{*}{$\mathrm{pT}_{22}$} & $\mathrm{R}$ & 0.88412 & 0.38423 & 0.96612 & 0.97412 & 0.97733 & 0.88911 \\
\hline & & $\mathrm{R} 2$ & 0.78167 & 0.14763 & 0.93339 & 0.94628 & 0.94731 & 0.79052 \\
\hline & & $\mathrm{p}$ & 0.05 & ns & 0.01 & 0.01 & 0.01 & 0.05 \\
\hline & \multirow[t]{3}{*}{$\mathrm{pT}_{23}$} & $\mathrm{R}$ & 0.93215 & 0.97346 & 0.79354 & 0.58421 & 0.74278 & 0.96542 \\
\hline & & $\mathrm{R}^{2}$ & 0.8689 & 0.94762 & 0.62971 & 0.3413 & 0.55172 & 0.93204 \\
\hline & & $\mathrm{p}$ & 0.01 & 0.01 & 0.05 & ns & 0.05 & 0.01 \\
\hline \multirow[t]{9}{*}{$\mathrm{C} 2$} & \multirow[t]{3}{*}{$\mathrm{pT}_{21}$} & $\mathrm{R}$ & 0.32145 & 0.31238 & 0.50156 & 0.16973 & 0.45672 & 0.37829 \\
\hline & & $\mathrm{R}^{2}$ & 0.10333 & 0.0969 & 0.25156 & 0.02881 & 0.20859 & 0.1431 \\
\hline & & $\mathrm{p}$ & ns & ns & ns & ns & ns & ns \\
\hline & \multirow[t]{3}{*}{$\mathrm{pT}_{22}$} & $\mathrm{R}$ & 0.82356 & 0.49324 & 0.94582 & 0.96374 & 0.91214 & 0.62569 \\
\hline & & $\mathrm{R}^{2}$ & 0.67825 & 0.24329 & 0.89458 & 0.9288 & 0.832 & 0.39149 \\
\hline & & $\mathrm{p}$ & 0.05 & ns & 0.01 & 0.01 & 0.01 & ns \\
\hline & \multirow[t]{3}{*}{$\mathrm{pT}_{23}$} & $\mathrm{R}$ & 0.96739 & 0.95678 & 0.94718 & 0.50047 & 0.81248 & 0.45768 \\
\hline & & $\mathrm{R}^{2}$ & 0.93584 & 0.91543 & 0.89715 & 0.25047 & 0.66012 & 0.20947 \\
\hline & & $\mathrm{p}$ & 0.01 & 0.01 & 0.05 & ns & 0.05 & ns \\
\hline \multirow[t]{9}{*}{$\mathrm{C} 3$} & \multirow[t]{3}{*}{$\mathrm{pT}_{21}$} & $\mathrm{R}$ & 0.45362 & 0.37288 & 0.51118 & 0.19463 & 0.47284 & 0.32145 \\
\hline & & $\mathrm{R}^{2}$ & 0.20577 & 0.13904 & 0.26131 & 0.03789 & 0.22358 & 0.10333 \\
\hline & & $\mathrm{p}$ & ns & ns & ns & ns & ns & ns \\
\hline & \multirow[t]{3}{*}{$\mathrm{pT}_{22}$} & $\mathrm{R}$ & 0.73246 & 0.30123 & 0.94378 & 0.94178 & 0.89236 & 0.64113 \\
\hline & & $\mathrm{R}^{2}$ & 0.53649 & 0.09074 & 0.89072 & 0.88695 & 0.79631 & 0.41105 \\
\hline & & $\mathrm{p}$ & 0.05 & ns & 0.01 & 0.01 & 0.01 & 0.05 \\
\hline & \multirow{3}{*}{$\mathrm{pT}_{23}$} & $\mathrm{R}$ & 0.98275 & 0.95467 & 0.79932 & 0.5101 & 0.80213 & 0.95467 \\
\hline & & $\mathrm{R}^{2}$ & 0.9658 & 0.9114 & 0.79389 & 0.2602 & 0.64341 & 0.9114 \\
\hline & & $\mathrm{p}$ & 0.01 & 0.01 & 0.05 & ns & 0.05 & 0.01 \\
\hline
\end{tabular}

\subsection{Analysis of PCA}

Multi-way chemometric analysis based on LF-NMR measurements was used to investigate the relationship of LF-NMR parameters and quality characteristics; PCA were highly considered in aquatic products among those methods [29-31]. Figure 4 demonstrated the component plot of the first two principal component PC1 and PC2 scores of HTS fillets during storage. In this case, $84.12 \%$ and $10.69 \%$ of the variability was explained by principal components PC1 and PC2, respectively. It can been seen that $\mathrm{pT}_{22}$, water content, fat content, and the activity of $\mathrm{Ca}^{2+}$-ATPase were located on the positive axis of $\mathrm{PC} 1$, which was consistent with the correlation of $\mathrm{pT}_{22}$ and special physiochemical parameters. Meanwhile, the $\mathrm{pT}_{23}, \mathrm{TVB}-\mathrm{N}, \mathrm{K}$ value, and MDA located on the negative axis of PC1 and also verified the results of linear regression analysis. Above all, the preliminary PCA showed that the $\mathrm{pT}_{22}$ parameter could be a candidate in characterizing the water and fat losses as well as enzyme activity of HTS fillets, while the $\mathrm{pT}_{23}$ parameter could replace the traditional TVB-N, K value, and MDA, although with some limitations. These results demonstrated that LF-NMR combined with PCA analysis has great potential in evaluate quality characteristics of HTS fillets during storage, which was confirmed previously [32-34]. 


\section{Component Plot in Rotated Space}

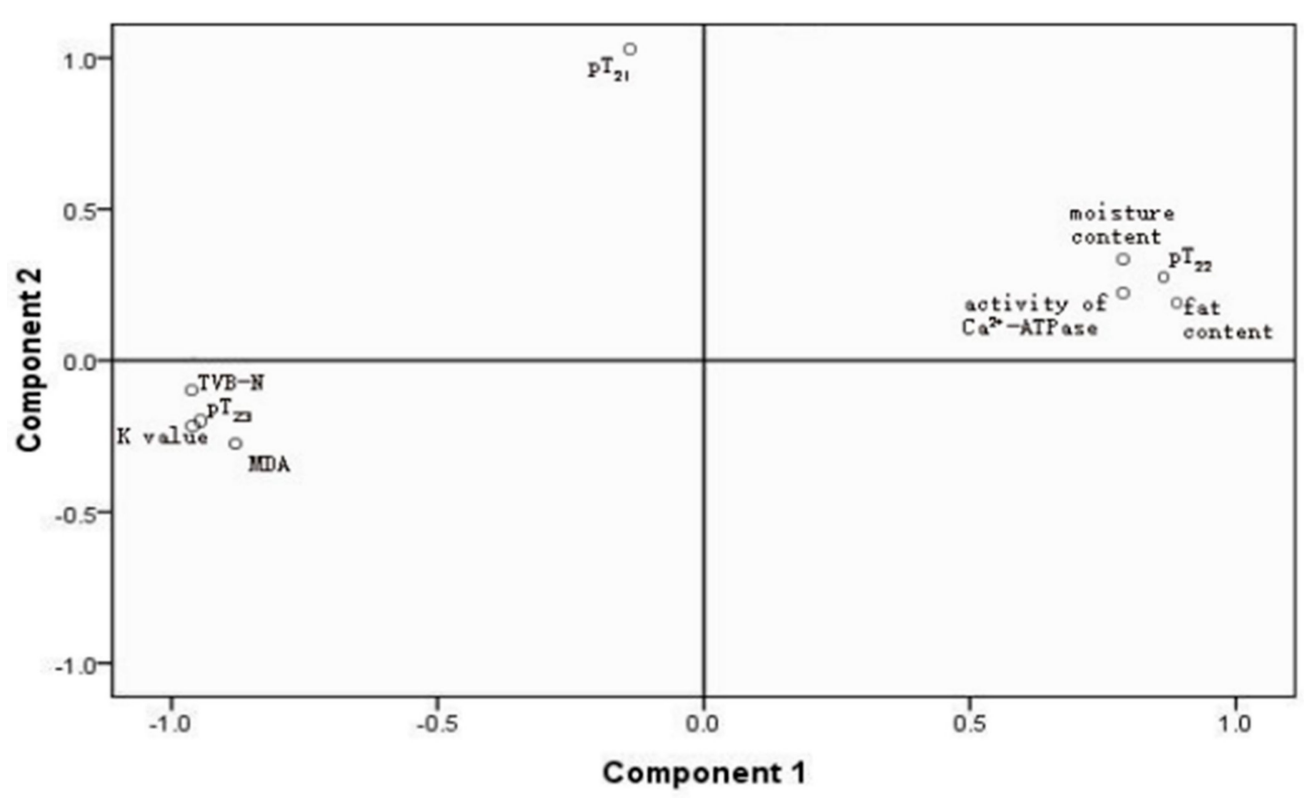

Figure 4. Principal component PC1 and PC2 score plot from the principal component analysis (PCA) of HTS fillets during refrigerated storage (CK1: distilled water + air packing; CK2: edible coating + air packing; $\mathrm{C} 1$ : edible coating $+\mathrm{MAP}\left(60 \% \mathrm{CO}_{2} / 40 \% \mathrm{~N}_{2}\right)$; C2: edible coating $+\mathrm{MAP}\left(65 \% \mathrm{CO}_{2} / 35 \% \mathrm{~N}_{2}\right)$; C3: edible coating + MAP $\left.\left(70 \% \mathrm{CO}_{2} / 30 \% \mathrm{~N}_{2}\right)\right)$.

\section{Conclusions}

The edible coating incorporated with MAP (gas composition of $70 \% \mathrm{CO}_{2} / 30 \% \mathrm{~N}_{2}$ ) has positive effects to maintain the excellent qualities/characteristics and extend shelf life for 8-12 days of HTS fillets during refrigerated storage. The water dynamic changes were evaluated by LF-NMR and MRI and three types of water were distinguished: bound water $\left(T_{21}\right)$, immobile water $\left(T_{22}\right)$, and free water $\left(\mathrm{T}_{23}\right)$. The $\mathrm{pT}_{22}$ diminished progressively while $\mathrm{pT}_{23}$ increased during storage, and $\mathrm{pT}_{22}$ accounted for the largest proportion of three types of water, followed by $\mathrm{pT}_{23}$. The weighted MRI provided the internal structure information associated with different treated samples during storage. We also demonstrated the excellent correlation of LF-NMR measurements and quality parameters based on the linear regression analysis and PCA. Above all, the combination of LF-NMR and MRI was able to give more information about water distribution and migration, demonstrating the feasibility of LF-NMR pulse MRI to monitor quality deterioration and predict shelf life of HTS fillets during refrigerated storage.

Author Contributions: Conceived and designed the experiments: N.L., J.M., and J.X. Performed the experiments: N.L., Y.S., and W.L. Analyzed the data: N.L., Y.S., and J.M. Wrote the paper: N.L. and J.M.

Funding: This research was funded by the National Natural Science Foundation of China (31601414), National Key Research and Development Program (2016YFD0400106), and Construction Project of Public Service Platform for Shanghai Municipal Science and Technology Commission (17DZ2293400).

Acknowledgments: The authors would like to express their profound gratitude to Weiqiang Qiu from the Instrumental Analysis Center of Shanghai Ocean University for his technical assistance.

Conflicts of Interest: The authors declare no conflicts of interest. 


\section{References}

1. Yu, D.; Xu, Y.; Regenstein, J.M.; Xia, W.; Yang, F.; Jiang, Q.; Wang, B. The effects of edible chitosan-based coatings on flavor quality of raw grass carp (Ctenopharyngodon idellus) fillets during refrigerated storage. Food Chem. 2018, 242, 412-420. [CrossRef] [PubMed]

2. Benbettaïeb, N.; Tanner, C.; Cayot, P.; Karbowiak, T.; Debeaufort, F. Impact of functional properties and release kinetics on antioxidant activity of biopolymer active films and coatings. Food Chem. 2017, 242, 369-377. [CrossRef] [PubMed]

3. Dehghani, P.; Hosseini, S.M.H.; Golmakani, M.T.; Majdinasab, M.; Esteghlal, S. Shelf-life extension of refrigerated rainbow trout fillets using total farsi gum-based coatings containing clove and thyme essential oils emulsions. Food Hydrocoll. 2018, 77, 677-688. [CrossRef]

4. Martínez, O.; Salmeron, J.; Epelde, L.; Vicente, M.S.; de Vega, C. Quality enhancement of smoked sea bass (Dicentrarchus labrax) fillets by adding resveratrol and coating with chitosan and alginate edible films. Food Control 2018, 85, 168-176. [CrossRef]

5. Mizielińska, M.; Kowalska, U.; Jarosz, M.; Sumińska, P. A comparison of the effects of packaging containing nano $\mathrm{ZnO}$ or polylysine on the microbial purity and texture of cod (Gadus morhua) fillets. Nanomaterials 2018, 8, 158. [CrossRef] [PubMed]

6. Hernández, E.J.G.P.; de Carvalho, R.N., Jr.; Joele, M.R.S.P.; Araújo, C.D.S.; Lourenço, L.F.H. Effects of modified atmosphere packing over the shelf life of sous vide, from captive pirarucu (Arapaima gigas). Innov. Food Sci. Emerg. Technol. 2017, 39, 94-100. [CrossRef]

7. Kuuliala, L.; Al Hage, Y.; Ioannidis, A.G.; Sader, M.; Kerckhof, F.M.; Vanderroost, M.; Boon, N.; Baets, B.D.; Meulenaer, B.D.; Ragaert, P.; et al. Microbiological, chemical and sensory spoilage analysis of raw Atlantic cod (Gadus morhua) stored under modified atmospheres. Food Microbiol. 2018, 70, 232-244. [CrossRef] [PubMed]

8. Odeyemi, O.A.; Burke, C.M.; Bolch, C.J.; Stanley, R. Evaluation of spoilage potential and volatile metabolites production by Shewanella baltica isolated from modified atmosphere packaged live mussels. Food Res. Int. 2018, 103, 415-425. [CrossRef] [PubMed]

9. Zang, X.; Lin, Z.; Zhang, T.; Wang, H.; Cong, S.; Song, Y.; Li, Y.; Cheng, S. Nondestructive measurement of water and fat contents, water dynamics during drying and adulteration detection of intact small yellow croaker by low field NMR. J. Food Meas. Charact. 2017, 11, 1550-1558. [CrossRef]

10. Sánchez-Alonso, I.; Martinez, I.; Sánchez-Valencia, J.; Careche, M. Estimation of freezing storage time and quality changes in hake (Merluccius merluccius L.) by low field NMR. Food Chem. 2012, 135, 1626-1634. [CrossRef] [PubMed]

11. Huang, L.; Song, Y.; Kamal, T.; Li, Y.; Xia, K.; Lin, Z.; Qi, L.; Cheng, S.; Zhu, B.; Tan, M. A non-invasive method based on low-field NMR to analyze the quality changes in caviar from hybrid sturgeon (Huso dauricus, Acipenser schrenckiid). J. Food Process. Pres. 2017, 41, e13256. [CrossRef]

12. Patel, K.K.; Khan, M.A.; Kar, A. Recent developments in applications of MRI techniques for foods and agricultural produce-An overview. J. Food Sci. Technol. MYS 2015, 52, 1-26. [CrossRef]

13. Albertos, I.; Martin-Diana, A.B.; Cullen, P.J.; Tiwari, B.K.; Ojha, S.K.; Bourke, P.; Rico, D. Shelf-life extension of herring (Clupea harengus) using in-package atmospheric plasma technology. Innov. Food Sci. Emerg. Technol. 2017. [CrossRef]

14. Sun, X.H.; Xiao, L.; Lan, W.Q.; Liu, S.C.; Wang, Q.; Yang, X.H.; Zhang, W.J.; Xie, J. Effects of temperature fluctuation on quality changes of large yellow croaker (Pseudosciaena crocea) with ice storage during logistics process. J. Food Process. Pres. 2018, 42, e13505. [CrossRef]

15. Su, H.; Wei, C.; Fu, S.; Chu, W.; Kai, L.; Huang, Z.; Li, J. Antimicrobial effect of bayberry leaf extract forthe preservation of large yellow croaker (Pseudosciaena crocea). J. Sci. Food Agric. 2013, 94, 935-942. [CrossRef] [PubMed]

16. Soares, N.; Silva, P.; Barbosa, C.; Pinheiro, R.; Vicente, A.A. Comparing the effects of glazing and chitosan-based coating applied on frozen salmon on its organoleptic and physicochemical characteristics over six-months storage. J. Food Eng. 2017, 194, 79-86. [CrossRef]

17. Wang, S.; Xiang, W.; Fan, H.; Xie, J.; Qian, Y.F. Study on the mobility of water and its correlation with the spoilage process of salmon (Salmo solar) stored at 0 and $4{ }^{\circ} \mathrm{C}$ by low-field nuclear magnetic resonance (LF NMR 1H). J. Food Sci. Technol. MYS 2018, 55, 173-182. [CrossRef] [PubMed] 
18. Gonçalves, A.A.; Santos, T.C.L. The effects of vacuum and modified atmosphere packaging on quality changes in seasoned cobia (Rachycentron canadum) sticks stored under refrigeration. Braz. J. Food Technol. 2018, 21, e2017029. [CrossRef]

19. Rahman, A.; Kondo, N.; Ogawa, Y.; Suzuki, T.; Shirataki, Y.; Wakita, Y. Prediction of K value for fish flesh based on ultraviolet-visible spectroscopy of fish eye fluid using partial least squares regression. Comput. Electron. Agric. 2015, 117, 149-153. [CrossRef]

20. Li, X.P.; Zhou, M.Y.; Liu, J.F.; Xu, Y.X.; Mi, H.B.; Yi, S.M.; Li, J.R.; Lin, H. Shelf-life extension of chilled olive flounder (Paralichthys olivaceus) using chitosan coatings containing clove oil. J. Food Process. Pres. 2017, 41, e13204. [CrossRef]

21. Li, Q.; Zhang, L.; Lu, H.; Song, S.; Luo, Y. Comparison of postmortem changes in ATP-related compounds, protein degradation and endogenous enzyme activity of white muscle and dark muscle from common carp (Cyprinus carpio) stored at $4{ }^{\circ} \mathrm{C}$. LWT Food Sci. Technol. 2017, 78, 317-324. [CrossRef]

22. Ozogul, Y.; Balikci, E. Effect of various processing methods on quality of mackerel (Scomber scombrus). Food Bioprocess Technol. 2013, 6, 1091-1098. [CrossRef]

23. Shariat, M.; Raftari, M.; Bakar, F.A. Evaluation of sensory and biochemical changes in fresh water catfish stored under vacuum and different modified atmospheres. Anal. Methods 2013, 5, 231-238. [CrossRef]

24. Masniyom, P.; Benjakul, S.; Visessanguan, W. ATPase activity, surface hydrophobicity, sulfhydryl content and protein degradation in refrigerated seabass muscle in modified atmosphere packaging. J. Food Biochem. 2004, 28, 43-60. [CrossRef]

25. Reza, M.S.; Bapary, M.A.; Ahasan, C.T.; Islam, M.N.; Kamal, M. Shelf life of several marine fish species of Bangladesh during ice storage. Int. J. Food Sci. Technol. 2009, 44, 1485-1494. [CrossRef]

26. Wang, S.; Lin, Z.; Xia, K.; Li, Y.; Tan, M. Dynamics of water mobility and distribution in Sur clam (Mactra chinensis) during dehydration and rehydration processes assessed by low-field NMR and MRI. J. Food Meas. Charact. 2017, 11, 1342-1354. [CrossRef]

27. Qin, N.; Zhang, L.; Zhang, J.; Song, S.; Wang, Z.; Regenstein, J.M.; Luo, Y. Influence of lightly salting and sugaring on the quality and water distribution of grass carp (Ctenopharyngodon idellus) during super-chilled storage. J. Food Eng. 2017, 215, 104-112. [CrossRef]

28. Li, H.; Lin, B.; Hong, Y.; Liu, T.; Huang, Z.; Wang, R.; Wang, Z. Assessing the moisture migration during microwave drying of coal using low-field nuclear magnetic resonance. Drying Technol. 2018, 36, 567-577. [CrossRef]

29. Brown, R.J.; Capozzi, F.; Cavani, C.; Cremonini, M.A.; Petracci, M.; Placucci, G. Relationships between (1)H NMR relaxation data and some technological parameters of meat: A chemometric approach. J. Magn. Reson. 2000, 147, 89-94. [CrossRef] [PubMed]

30. Li, T.; Tu, C.; Rui, X.; Gao, Y.; Li, W.; Wang, K.; Xiao, Y.; Dong, M. Study of water dynamics in the soaking, steaming and solid-state fermentation of glutinous rice by LF-NMR: A novel monitoring approach. J. Agric. Food Chem. 2015, 63, 3261-3270. [CrossRef] [PubMed]

31. Huang, L.; Cheng, S.; Song, Y.; Xia, K.; Xu, X.; Zhu, B.W.; Tan, M. Nondestructive analysis of caviar compositions using low-field nuclear magnetic resonance technique. J. Food Meas. Charact. 2016, 11, 621-628. [CrossRef]

32. Xia, K.; Xu, W.; Huang, L.; Song, Y.; Zhu, B.W.; Tan, M. Water dynamics of turbot flesh during frying, boiling, and stewing processes and its relationship with color and texture properties: Low-field NMR and MRI studies. J. Food Process. Pres. 2018, 42, e13338. [CrossRef]

33. Li, J.; Xia, K.; Li, Y.; Tan, M. Influence of freezing-thawing cycle on water dynamics of turbot flesh assessed by low-field nuclear magnetic resonance and magnetic resonance imaging. Int. J. Food Eng. 2018, 14, 14. [CrossRef]

34. Li, M.; Li, B.; Zhang, W. Rapid and non-invasive detection and imaging of the hydrocolloid-injected prawns with low-field NMR and MRI. Food Chem. 2018, 242, 16-21. [CrossRef] [PubMed]

(C) 2018 by the authors. Licensee MDPI, Basel, Switzerland. This article is an open access article distributed under the terms and conditions of the Creative Commons Attribution (CC BY) license (http:// creativecommons.org/licenses/by/4.0/). 